\title{
Nouvelles infections émergentes: Impact sur la santé de l'enfant
}

\author{
Jean M. van Seventer ${ }^{a} \quad$ Amanda DeLoureiro $^{b}$ Davidson H. Hamer ${ }^{c, d}$ \\ Départements de la a Santé de l'Environnement et ${ }^{b}$ Santé internationale, Boston University School of Public Health, \\ et ${ }^{\complement}$ Centre pour la Santé globale et le Développement, Boston University Schools of Public Health and Medicine, et \\ ${ }^{\mathrm{d}}$ Tufts University Friedman School of Nutrition Science and Policy, Boston, Mass., États-Unis
}

\section{Mots-clés}

Grippe aviaire, maladies infectieuses • Grippe porcine

\section{Résumé}

L'interaction complexe de facteurs humains et environnementaux (facteurs écologiques, génétiques, politiques et socioéconomiques) est responsable de l'émergence et la réémergence de maladies infectieuses. Ces facteurs ont souvent un effet particulier sur les enfants et par conséquent, les infections émergentes peuvent avoir des effets spécifiques sur les populations pédiatriques en termes de santé physique et mentale mais aussi de bien-être social. Les enfants sont les acteurs les plus vulnérables de notre société. Afin de les protéger au mieux de l'impact des maladies émergentes, il est impératif de comprendre comment les facteurs déterminant l'émergence de maladies et les maladies émergentes elles-mêmes peuvent les affecter. Cela nous permettra de nous concentrer sur les mesures les plus adéquates, non seulement pour prévenir l'infection des populations pédiatriques mais aussi pour mettre au point le traitement et les soins à dispenser en cas d'émergence d'une maladie infectieuse. La grippe est le prototype même de la maladie émergente/réémergente. L'épidémie de grippe réémerge chaque année entre les périodes de pandémies grippales. À la fois épidémique et pandémique, la grippe peut avoir des effets considérables sur le bien-être des enfants. Depuis une di- zaine d'années, nous craignons des mutations du virus de la grippe aviaire (H5N1) le rendant capable de se transmettre efficacement entre I'homme et nous nous préparons à une pandémie de grippe virulente. Le potentiel pandémique de la grippe aviaire ne s'est pas (encore) concrétisé mais les efforts de préparation à une pandémie de grande ampleur n'ont pas été vains. En effet, l'émergence inattendue et la propagation rapide de la grippe porcine $\mathrm{A}(\mathrm{H} 1 \mathrm{~N} 1)$ a entraîné une pandémie mondiale qui a déjà eu de profonds effets sur les enfants et les adultes. Les écoles et les crêches, les moyens de transports modernes et les voyages internationaux ont facilité la propagation de cette nouvelle souche du virus de la grippe. La grippe porcine illustre bien comment l'intéraction des facteurs environnementaux et humains conduisent à l'émergence d'une maladie infectieuse avec des effets spécifiques sur les enfants.

Copyright $\odot 2010$ Nestec Ltd., Vevey/S. Karger AG, Basel

\section{Introduction}

Au cours du vingtième siècle, les maladies infectieuses émergentes ont été de mieux en mieux diagnostiquées. Le nombre de cas de nouvelles maladies émergentes a augmenté régulièrement entre 1940 et 1990 pour décroître légèrement au cours de la dernière décennie, malgré les progrès pour les repérer (meilleures méthodes de dia-

\section{KARGER}

Fax +41613061234

E-Mail karger@karger.ch

www.karger.com (c) 2010 Nestec Ltd., Vevey/S. Karger AG, Basel

0250-9644/09/0673-0105\$26.00/0

Accessible en ligne à:

www.karger.com/anf
Prof. Davidson H. Hamer, MD, Center for Global Health and Development Boston University Schools of Public Health and Medicine Tufts University Friedman School of Nutrition Science and Policy 3rd floor Crosstown, 801 Massachusetts Avenue, Boston, MA 02118 (USA) Tel. +1 617414 1267, Fax +1 617414 1261, E-Mail dhamer@ bu.edu 
gnostique, et une amélioration de la surveillance) [1]. Ces maladies ont des répercussions significatives sur les systèmes de santé et l'économie mondiale $[2,3]$. Tandis que l'émergence des pathogènes viraux tels que le virus Ebola et la grippe aviaire a fait l'objet d'une très grande attention dans la presse généraliste et les publications scientifiques, l'analyse attentive des cas de maladies infectieuses émergentes a révélé que les bactéries et la rickettsie représentaient plus de la moitié des cas [1]. L'interaction complexe de facteurs environnementaux, écologiques, génétiques, politiques et socioéconomiques est responsable del'émergence ou la réémergence des maladies infectieuses.

\section{Résumé des facteurs favorisant l'émergence des maladies}

L'émergence d'une maladie infectieuse nécessite non seulement une interaction compatible entre hôte et pathogène mais également des conditions humaines et environnementales appropriées. Dans cet article nous examinons l'impact des facteurs environnementaux et humains sur la transmission et la propagation des maladies émergentes et réémergentes et nous nous intéressons à la manière dont ces maladies affectent les enfants. Lorsqu'on étudie les maladies émergentes, il est important de garder à l'esprit que les véritables nouvelles maladies émergentes sont rares et que la plupart de ces maladies sont en fait des maladies qui réémergent en raison de la présence de facteurs environnementaux et humains favorisant leur apparition.

\section{Facteurs environnementaux}

\section{Projets liés à l'eau}

Les activités humaines qui entraînent des changements dans la manière d'utiliser l'eau sont un facteur clé pouvant entraîner l'émergence de maladies infectieuses. L'irrigation est utilisée pour la production de cultures urbaines et elle nécessite la construction de barrages. Elle peut par conséquent amener l'eau dans des régions précédemment caractérisées par un faible taux de pluviométrie et dans lesquelles il y a généralement peu d'eau stagnante. Or, cette eau stagnante favorise l'émergence de maladies en créant des foyers de reproduction pour certains insectes. Les projets liés à l'eau jouent donc un rôle dans l'émergence des maladies transmises par des insectes, comme le paludisme, la schistosomiase, la dengue et le chikungunya. Par exemple, la construction du bar- rage hydroélectrique Gilgel-Gibe en Ethiopie a entraîné une prévalence plus élevée du paludisme parmi les enfants vivant près du barrage comparés à ceux vivant plus loin [4]. De la même façon, les projets d'irrigation urbaine en Afrique de l'ouest ont été associés à une augmentation des taux de transmission du paludisme [5]. Les projets majeurs de contrôle de l'eau tels que le barrage de la rivière Erinle au Nigéria et le barrage des Trois Gorges en Chine ont conduit ou devraient conduire à la réémergence de la schistosomiase, qui touche souvent en priorité les jeunes enfants $[6,7]$.

\section{Fluctuations climatiques}

Les conditions climatiques, telles que la température et les précipitations, peuvent également avoir un impact sur l'émergence de maladies. Des cas extrêmes comme les tremblements de terre, les tsunamis, ou les éruptions volcaniques peuvent modifier le climat de telle sorte que cela puisse favoriser l'émergence d'une nouvelle maladie ou la réémergence d'une maladie précédemment identifiée, mais sous une forme plus virulente [8-10]. Par exemple, le tsunami de 2005 qui a touché Aceh (Sumatra, Indonésie) a entraîné l'éclosion d'une épidémie de tétanos chez les survivants blessés [11]. De même la contamination des sources d'eau potable suite au tremblement de terre du Kashmir en 2005 a entraîné une éclosion de rotavirus responsable de maladies diarrhéiques aiguës chez les nourrissons et les jeunes enfants [12]. Des phénomènes saisonniers ou cycliques tels que El Niño peuvent également avoir une influence sur l'émergence de maladies [13]. Il s'avère aussi de plus en plus probable que si la tendance à la hausse régulière de la moyenne des températures à la surface de la terre se confirme, la prévalence de nombreuses maladies va augmenter, telles que la schistosomiase, la leishmaniose, la maladie de Lyme, la dengue et l'encéphalite transmise par les tiques [14].

Les changements de l'épidémiologie des maladies infectieuses associées au phénomène El Niño fournissent d'excellents exemples pour illustrer l'interaction entre les variations climatiques et l'émergence de maladies. ENSO (El Niño Southern Oscillation) est un système instable climat/océan qui se développe dans l'océan Pacifique tous les 5 ans en moyenne (entre 2 et 7 ans) et produit des variations climatiques à court terme pouvant se manifester pendant 4 ou 5 ans [16]. Le cycle de réchauffement (El Niño) et de refroidissement (La Niña) de la température de la surface de l'eau dans l'océan pacifique tropical provient des modifications de la circulation de l'océan (les eaux froides du courant Humboldt, riches en nutriments, laissent place à un courant chaud venant du Pacifique 
Équatorial se dirigeant vers l'est et pauvre en nutriments). Le nombre de personnes touchées par des catastrophes naturelles est 13 à 20 fois plus élevé durant la première et la deuxiéme année de El Niño que dans l'année précédant son apparition [17]. Les rapports entre catastrophes naturelles et ENSO sont plus marqués en Asie du Sud et de l'Est et en Afrique subsaharienne. Des recherches ont montré que les catastrophes naturelles et la modification des schémas de précipitations suite à ENSO déclenchent l'émergence de maladies dans de nombreuses régions du monde. La grippe, par exemple, est un problème plus courant pendant le phénomène ENSO [18]. Les variations climatiques liées à El Niño ont été associées à l'émergence d'épidémies d'un certain nombre de maladies transmises par des vecteurs et des rongeurs, à savoir l'hantavirus, le paludisme, la dengue, la fièvre de la vallée du Rift, la polyarthrite épidémique due au virus Ross River et l'encéphalite due au flavivirus de Murray Valley [13, 17, 19-21].

\section{Changements dans la manière d'utiliser la terre}

L'urbanisation, la déforestation, la reforestation, et les migrations vers des régions non e xploitées ont rapproché les hommes des vecteurs de maladies et des pathogènes. Par exemple, une étude menée au Taïwan a montré qu'une augmentation de l'urbanisation était associée à une élevation de l'incidence de la dengue [22]. Ces dernières décennies, l'émergence de la maladie de Lyme est un exemple de l'impact de la reforestation, qui a rapproché le vecteur de cette maladie et les populations humaines. Le cerf, porteur potentiel de tiques vecteurs de cette maladie, vit à l'orée des forêts et dans les prairies à proximité des lieux où sont nés les projets de construction humains de ces dernières décennies [23]. Les enfants jouant dans les régions forestières près de leurs demeures suburbaines sont ainsi de plus en plus exposés à la bactérie Borrellia burgdorferi, agent responsable de la maladie de Lyme. De manière similaire, l'encéphalite transmise par les tiques a réémergé en Russie à partir du moment où les habitants des villes ont commencé à occuper des résidences secondaires à la campagne (Dacha), les rapprochant des tiques de la forêt [15].

\section{Facteurs écologiques}

Les itinéraires des oiseaux migrateurs peuvent être responsables de l'introduction d'une maladie infectieuse dans une région jusqu'alors épargnée. Un exemple récent fut la propagation du virus du Nil occidental par les oiseaux migrateurs sur tout le territoire des États-Unis en l'espace de quelques années, un phénomène facilité par la présence de moustiques, vecteurs de la maladie à travers tous les États-Unis [24, 25]. Il se peut aussi que la concurrence intra-espèce pour se procurer de la nourriture contribue à l'émergence de maladies infectieuse en rapprochant les vecteurs de maladies des populations humaines, augmentant ainsi le risque d'infection humaine. Ceci explique vraisemblablement l'épidémie à hantavirus Sin Nombre (1993) qui toucha la région des Four Corners aux États-Unis à cause d'une explosion démographique du réservoir de l'hantavirus local, la souris sylvestre. Cette explosion démographique faisait suite à une augmentation des réserves de nourriture de ce rongeur, conséquence du phénomène El Niño $[13,26]$.

Alors que l'on a démontré que l'utilisation étendue des antibiotiques favorisait le développement d'une résistance bactérienne (voir ci-dessous) et exerçait ainsi une pression sélective sur les micro-organismes (bactérie et mycobactérie en particulier), certaines formes d'évolution microbienne semblent être apparues suite à une adaptation génétique microbienne à de nouveaux environnements. Par exemple, ces 50 dernières années ont vu l'émergence d'Escherichia coli O157:H7, à l'origine d'intoxications alimentaires avec d'importantes diarrhées hémorragiques et un syndrome hémolytique et urémique. Cette espèce d'E. coli a acquis des gènes de Shigella qui ont renforcé sa pathogénicité car codant pour des toxines $[21,27]$. E. coli O157:H7 est ainsi de plus en plus associé aux épidémies causées par différents aliments et boissons ou par contact rapproché avec les animaux domestiques de la ferme. Les jeunes enfants infectés par cette bactérie et présentant un syndrome hémolytique et urémique ont alors un risque élevé de développer une insuffisance rénale aiguë [28].

\section{Facteurs humains}

\section{Facteurs comportementaux}

Les mauvaises habitudes d'hygiène de vie, notamment le tabagisme, la consommation de drogue, l'abus d'alcool et le vagabondage sexuel sont des facteurs de risque significatifs dans l'émergence de certaines maladies infectieuses. Les facteurs économiques et sociaux encourageant les relations hétérosexuelles avec de multiples partenaires ont ainsi facilité la propagation du virus d'immuno-déficience humaine (VIH) dans certaines régions d'Afrique dans les années 1980 et 1990 [29]. Des analyses plus récentes des réseaux sexuels ont montré que les relations sexuelles avec plusieurs partenaires facilitent la propagation du VIH dans de nombreuses régions de 
l'Afrique subsaharienne [30]. Par ailleurs, l'utilisation de drogues injectables est un facteur de risque important dans l'émergence des maladies infectieuses transmises par le sang telles que l'hépatite B ou C et le VIH. Par exemple, une étude canadienne a montré que l'injection de cocaïne était un facteur de risque majeur d'infection par le VIH-1 [31]. De même, il a été rapporté qu'une infection par le Leishmania infantum avait touché des toxicomanes en Espagne suite au développement inhabituel d'un cycle anthropophile de ce parasite protozoaire [32]. Certaines habitudes alimentaires ont également été rendues responsables d'une augmentation du risque d'infection par certains agents pathogènes. En effet, la consommation de poisson cru ou à peine cuit sous la forme de ceviches, sushis ou frittures est associée à l'infection par le parasite Pseudoterranova decipiens au Chili [33]. De la même manière en Espagne, une augmentation du nombre de cas d'anisakiase a été identifiée suite à la consommation d'anchois crus et de poisson à peine cuit [34].

Certaines activités de loisirs peuvent aussi augmenter le risque d'être exposé à des maladies infectieuses. La transmission de maladies lors d'activités aquatiques est bien connue, comme par exemple ces deux centres de loisir du Missouri dont les enfants ont été victimes d'une éclosion de cryptosporidiose après avoir nagé dans des eaux contaminées [35]. De même dans les îles de Yaeyama au Japon, des individus furent infectés par la leptospirose en participant à des sports nautiques tels que le canoë et le kayak [36]. Les activités d'aventures extrêmes ont également entraîné l'émergence de cas de leptospirose chez les participants de la course-expédition Eco-Challenge à Bornéo et de schistosomiase chez les rafteurs d'Éthiopie $[37,38]$.

\section{Crèches}

Les changements de modes de travail peuvent également contribuer à l'émergence de maladies. Les familles à double revenu et les foyers monoparentaux sont de plus en plus nombreux; ils ont besoin de structures d'accueil pour leurs enfants, telles que les crèches, qui, par conséquent, se développent de plus en plus. Les épidémies d'infection respiratoire aiguë et de maladies diarrhéiques ne sont pas rares dans ces établissements de garde d'enfants. La fréquentation des crèches est d'ailleurs un facteur de risque connu favorisant le développement du virus respiratoire syncytial (VRS) et du virus de la grippe [39-41]. Dans une étude sur les épidémies entériques dans les crèches, E. coli O157:H7 fut identifié comme le pathogène le plus courant responsable de maladie grave necessitant l'hospitalisation [42].

\section{Facteurs culturels}

Les normes culturelles telles que les pratiques d'inhumation ou la consommation de nourriture peuvent également avoir des répercussions sur l'émergence de maladies. Durant une épidémie de la fièvre hémorragique Ebola en Ouganda, la plupart des membres de la communauté qui sont tombés malades sont ceux qui ont été exposés au virus au cours des rituels funéraires traditionnels consistant à laver le cadavre avant l'inhumation [43]. Afin de limiter l'épidémie, les pratiques d'inhumation traditionnelles furent interdites et remplacées par des procédés plus sûrs. Par ailleurs, la surpopulation, combinée à la dénutrition et à l'arrêt du traitement contre la tuberculose $(\mathrm{Tb})$ sont autant de facteurs ayant contribué à l'augmentation de l'incidence de $\mathrm{Tb}$ multirésistante dans les prisons de l'ex-Union soviétique. Il a également été rapporté que le taux d'incarcération est un facteur déterminant dans l'augmentation des cas de $\mathrm{Tb}$ et de $\mathrm{Tb}$ multirésistante en Europe et en Asie centrale [44-46]. Le contact avec les prisonniers est aussi un important facteur dans l'introduction de la $\mathrm{Tb}$ en dehors du milieu carcéral $[47,48]$.

\section{Démographie}

Le vieillissement des populations est associé à l'augmentation de la prévalence et de la gravité des pneumonies, des bactérémies et autres maladies infectieuses, avec un risque accru de mortalité, l'immunosénescence augmentant la sensibilité aux maladies [49]. Cette dégradation progressive des fonctions immunitaires chez les patients en long séjour ou vivant dans des institutions telles que les maisons de retraite a été associée à des épidémies de norovirus, de grippe et d'infection au streptocoque du groupe A invasif [50,51].

La présence de familles nombreuses est encore le fait de beaucoup de pays en voie de développement et, par conséquent, une part importante de la population est très jeune. Ceci peut avoir un impact sur l'émergence de maladies infectieuses, les nourrissons et les enfants étant particulièrement sensibles à de nombreuses maladies hautement contagieuses, en termes d'acquisition et de virulence, en raison de leur «naïveté immunologique» [52, 53].

\section{Voyages et transports}

Les voyages à destination ou en provenance de régions exotiques ont contribué à la propagation rapide de maladies. Par exemple, un citoyen Danois non vacciné qui avait voyagé au Népal et en Inde avait contracté la rougeole et à son retour au Danemark l'avait transmise à 
quatre autres individus. Des voyageurs ont également été impliqués dans la propagation de virus respiratoires (tel que le syndrome respiratoire aigu sévère ou SRAS) et du virus chikungunya [54, 55].

L'immigration peut aussi avoir un impact sur l'émergence des maladies, les immigrants pouvant être porteurs de pathogènes et ainsi transmettre les maladies dans une région jusqu'à l'épargnée. Nous pouvons citer en exemple les immigrants de la République Dominicaine et d'Inde qui sont à l'origine de deux épidémies de $\mathrm{Tb}$ à Barcelone en Espagne durant la période 1999-2000 [56]. Les travailleurs migrants peuvent avoir un impact similaire sur l'émergence de maladies car ces personnes peuvent être amenées à parcourir de longues distances à la recherche d'un emploi et peuvent par conséquent transporter des maladies vers des régions où ces maladies étaient inexistantes. La réémergence ces dix dernières années de la poliomyélite dans de nombreux pays de l'Afrique subsaharienne est la conséquence des voyages internes dans cette région, combinés à une réduction de la vaccination contre cette maladie [57].

Les adoptions au niveau international peuvent également favoriser l'émergence de maladies, en particulier si les enfants adoptés présentent des pathologies qui n'existent pas dans leur pays d'accueil. L'éventualité de propagation de maladies infectieuses par des enfants adoptés à l'étranger est illustrée par un cas de rougeole observé chez un étudiant américain non immunisé qui avait été en contact avec l'un des dix enfants adoptés, tous originaires d'un même orphelinat chinois et infectés par la rougeole [58].

Historiquement, la guerre a aussi eu une influence sur l'émergence de maladies. On a supposé que l'émergence mondiale de la tristement célèbre grippe espagnole de 1918-1919 fut le résultat de mouvements de troupes pendant la première guerre mondiale. L'épidémie s'est en effet déclarée sur le front et s'est par conséquent propagée à travers le monde au retour des soldats [59].

Le commerce international peut également avoir une influence sur l'émergence des maladie, comme cela fut le cas en 2003 aux États-Unis lorsqu'une épidémie d'orthopoxvirose simienne (ou variole du singe) fut associée à l'importation de rongeurs d'Afrique de l'Ouest [60]. Ces rongeurs ont transmis la maladie à d'autres rongeurs que sont les chiens de prairie (Cynomys) qui ont ensuite servi de vecteurs pour transmettre la maladie à l'homme. Cette épidémie a surtout touché les enfants qui étaient au contact de ces nouveaux animaux de compagnie exotiques.

Nouvelles infections émergentes: Impact sur la santé de l'enfant

\section{Technologie}

L'amélioration des techniques médicales a permis d'augmenter la survie des individus gravement malades. Beaucoup d'entre eux sont très exposés au risque de contracter une des nombreuses maladies infectieuses émergentes encore peu répandues. Les personnes concernées sont celles atteintes du VIH, les personnes ayant subi une transplantation d'organe ou de moelle osseuse, celles sous thérapie immunosuppressive ou sous chimiothérapie dans le cadre d'un traitement contre le cancer. Ainsi, l'immunosuppression et l'exposition aux antibiotiques ont en partie favorisé le développement de Clostridium difficile qui est devenu la principale cause de diarrhée et de mortalité nosocomiales dans de nombreux pays industrialisés $[61,62]$. Ces dernières années, la mutation de cette bactérie a donné naissance à une nouvelle souche, ribotype 027 , épidémique, toxinogène particulièrement virulente et pathogène, notamment en raison de sa résistance plus importante aux fluoroquinolones $[61,62]$. De plus, au cours des trentes dernières années, l'épidémie du SIDA a entraîné l'émergence ou la réémergence de plusieurs pathogènes jusque là très rares ou non identifiés comme, entre autres, les mycobactéries atypiques Penicillium marneffei et Encephalitozoon intestinalis [63-65].

D'autres progrès technologiques récents peuvent avoir une influence sur l'émergence de maladies infectieuses. Par exemple, la climatisation et les moustiquaires peuvent limiter l'entrée d'insectes vecteurs de maladies dans les habitations. Ainsi, dans une étude comparant les cas de dengue dans les villes frontalières de Brownsville (Texas, États-Unis) et Matamoros (Mexique), des chercheurs ont conclu que l'absence de climatisation dans les maisons augmentait le risque d'une infection par la dengue.

La plomberie et les systèmes de refroidissement peuvent aussi conduire à l'émergence de maladies. Par exemple, les tours de refroidissement ont été associées à des épidémies de Legionella pneumophila. En Espagne, une telle épidémie a infecté des individus situés à $3,4 \mathrm{~km}$ du foyer de l'infection.

\section{Facteurs économiques}

Des considérations économiques doivent également être prises en compte lors d'une étude sur l'émergence des maladies infectieuses. Pour de nombreux individus, un faible revenu est souvent associé à une alimentation peu variée en termes de macro- et micronutriments. La dénutrition qui en découle, tant chez les enfants que chez les adultes, est alors responsable d'une augmentation du risque de contracter des maladies infectieuses encore plus

Ann Nestlé [Fr] 2009;67:105-121 
graves. Par exemple, une maladie apparue ces deux dernières décennies, la cryptosporidiose, s'avère plus grave, plus longue et plus difficile à traiter chez les adultes et les enfants dénutris ou avec un système immunitaire affaibli [66].

La pauvreté économique, souvent exacerbée par les guerres civiles ou la corruption, peut entraîner l'effondrement des infrastructures de santé publique. Ne bénéficiant que très peu d'un soutien moral ou financier de leur gouvernement, ces systèmes de santé, également victimes d'un manque de personnel, ne seront pas en mesure de mettre en place des campagnes d'éducation et de prévention pour prévenir les épidémies de maladies infectieuses. Les immunisations élémentaires, notamment les vaccins contre la rougeole, les oreillons, la rubéole, la poliomyélite, l'hépatite $\mathrm{B}$, la fièvre jaune et le méningocoque ne sont pas toujours disponibles dans ces régions dépourvues de toute politique de santé publique. Les gouvernements n'ayant pas la volonté de financer les mesures de surveillance, ces dernières sont inefficaces et représentent un problème majeur dans ces régions pauvres.

\section{Résistance antimicrobienne}

La résistance aux antibiotiques peut être le résultat de l'acqusition de gènes résistants issus d'autres organismes, d'une infection par des plasmides ou de mutations génétiques. L'utilisation massive d'antibiotiques a été associée à l'émergence d'une résistance à ces médicaments pour un large éventail de pathogènes infectieux, tels que Staphylococcus aureus, Salmonella enterica serovar Typhi et Pseudomonas aeruginosa. Un exemple flagrant est celui d'un traitement quasi systématique des infections des voies respiratoires hautes chez l'enfant par des antibiotiques alors que ces infections sont très souvent virales. La conséquence de cette abus a été le développement d'une résistance aux macrolides et à la pénicilline de Streptococcus pneumoniae $[67,68]$. De même, la pression sélective exercée par l'utilisation d'antibotiques à large spectre dans les établissements de santé a causé l'émergence d'organismes multirésistants tels que Klebsiella pneumoniae et $P$. aeruginosa, résistants à pratiquement tous les antibiotiques disponibles dans les pays riches. Malheureusement, des problèmes similaires accablent maintenant également les pays en voie de développement, comme l'a montré une récente étude sur les infections néonatales graves aux Phillippines [69].

La transformation des aliments et les pratiques agricoles ont aussi eu un impact sur l'émergence de maladies infectieuses. La surutilisation des antibiotiques chez les animaux de la ferme a conduit à l'apparition de bactéries particulièrement multirésistantes comme la Salmonella et le Campylobacter résistant aux fluoroquinolones [70, 71]. Ces agents peuvent se transmettre à l'homme et causer des infections souvent difficiles à traiter. Il y a en effet malheureusement d'innombrables exemples de ce type de transmission du bétail ou de la volaille vers l'homme [72]. La transmission d'isolats de salmonella résistants à la ceftriaxone du bétail à l'homme n'a, jusqu'à présent, été que très rarement observé aux États-Unis. Pourtant un cas d'infection par Salmonella typhimurium chez un garçon de 12 ans, résistante à un total surprenant de 13 antibiotiques (dont la ceftriaxone) devrait faire l'objet d'une attention très particulière [73].

L'émergence des bactéries résistantes aux antibiotiques et leur transmission de la ferme à la table de cuisine montre bien l'interaction complexe des différents facteurs responsables de l'émergence et la réémergence des maladies infectieuses. La mauvaise utilisation des antibiotiques comme agents promoteurs de croissance, combinées avec une distribution généralisée des produits alimentaires transformés et contaminés par des organismes tels que les salmonelles non typhoïdiques résistantes aux antibiotiques, a conduit à des épidémies multinationales de salmonellose [74].

\section{Résumé}

L'interaction complexe de facteurs de risque environnementaux, sociétaux, et individuels est responsable de l'émergence et de la réémergence de maladies. Les enfants sont particulièrement vulnérables et, une fois infectés, présentent des taux de morbidité et mortalité élevés. Il existe ainsi de remarquables exemples de l'impact négatif des maladies émergentes chez l'enfant, telle que la pandémie récente de grippe porcine $\mathrm{H} 1 \mathrm{~N} 1$ qui montre comment l'interaction de plusieurs de ces facteurs a conduit à la propagation mondiale d'une nouvelle variante de la grippe. La deuxième partie de cet article est consacré à la grippe et son impact sur la santé de l'enfant, avec ensuite un bref résumé sur la mortalité et la morbidité dues à la grippe aviaire (virus H5N1) et à la nouvelle grippe porcine $\mathrm{A}(\mathrm{H} 1 \mathrm{~N} 1)$.

\section{La grippe}

Les virus de la grippe, principaux responsables des infections respiratoires humaines, sont les agents infectieux respiratoires les plus pathogènes car ils sont à l'origine 
d'une morbidité et d'une mortalité élevées. Les enfants sont les plus vulnérables et jouent un rôle central dans l'introduction de la maladie dans les foyers et dans sa propagation [53, 75-83]. Alors que la grippe cause le taux de mortalité le plus important dans la population âgée, elle est à l'origine d'une importante morbidité chez les enfants, particulièrement de moins de 5 ans $[81,82,84,85]$. En comparaison avec des adultes âgés de 18 à 54 ans, les patients pédiatriques affectés par la grippe présentent plus de risques d'être hospitalisés (en hôpital de jour et aux urgences), et également plus de risques de complications ou de mortalité $[85,86]$.

La grippe saisonnière (épidémique, interpandémique) fait référence aux épidémies du virus de la grippe réémergeant chaque année sous une forme légèrement modifiée, contre laquelle la population a une immunité résiduelle. Une saison grippale typique se traduit par 250000 à 500000 décès dans le monde entier et approximativement 200000 hospitalisations et 36000 décès aux ÉtatsUnis $[87,88]$. La grippe pandémique fait référence à une épidémie de grippe mondiale causée par l'émergence d'une nouvelle souche de virus avec une structure antigénique différente qui se transmet rapidement en raison d'une absence ou quasi absence d'immunité pré-existante. L'épidémie de grippe la plus sérieuse jamais enregistrée, la grippe espagnole de 1918, tua jusqu'à 50 millions de personnes dans le monde entier $[86,89]$.

\section{Biologie du virus de la grippe}

Les virus de la grippe appartiennent à la famille des Orthomyxoviridae et se composent de trois principaux types de virus, $A, B$ et $C$. Les virus de la grippe $A$ et $B$ sont tous deux associés aux épidémies saisonnières alors que les virus de la grippe $\mathrm{C}$ sont endémiques et généralement sans grande conséquence pour l'homme. Les virus de la grippe de type A sont de loin les plus pathogènes chez l'homme car ils sont souvent associés à des maladies graves et sont responsables à la fois d'épidémies et de pandémies périodiques, comme en témoigne l'actuelle pandémie de grippe $\mathrm{A}(\mathrm{H} 1 \mathrm{~N} 1)$ d'origine porcine apparue en 2009.

Les virus de la grippe se définissent par une structure antigénique de deux glycoprotéines de surface, l'hémagglutinine (HA) et la neuraminidase (NA) [90, 91]. Il y a 16 protéines $\mathrm{HA}$ et 9 protéines NA qui se combinent pour donner naissance à différents sous-types de grippe $\mathrm{A}$ (tels que $\mathrm{H} 5 \mathrm{~N} 1$ et $\mathrm{H} 1 \mathrm{~N} 1$ ). La protéine $\mathrm{HA}$ permet de fixer le virus aux cellules épithéliales respiratoires et la protéine NA de le libérer. Ces deux protéines sont importantes non seulement pour la pathogénèse de la maladie mais aussi pour générer des réponses immunitaires [92]. Les deux glycoprotéines sont ainsi deux éléments essentiels du virus de la grippe.

Les virus de la grippe A peuvent être extrêmement dangereux pour l'homme en raison de leur capacité à évoluer très rapidement pour se transformer en un autre type de virus extrêmement virulent, nouveau d'un point de vue immunologique et qui peut déclencher une pandémie mondiale s'il est véritablement inédit. Le génome du virus de la grippe A se compose de 8 segments d'ARN, simple-brin, de polarité négative. Deux caractéristiques clés du génome viral permettent d'expliquer l'évolution rapide de ces virus: (1) l'absence d'enzymes réparatrices d'où un taux élevé d'erreurs de copie (mutations) lors de la réplication virale, et (2) la segmentation du génome ARN viral qui permet l'échange de segments d'ARN (recombinaison génétique) entre les espèces humaines et animales si plus d'un seul type de virus grippal infecte une cellule unique. On parle de «antigenic drift» pour désigner l'accumulation de petites mutations dans les séquences HA et NA, responsables des épidémies de grippes annuelles dans les populations partiellement immunisées. "Antigenic shift» survient plus rarement et correspond à une variation plus brutale et plus importante du virus de la grippe $\mathrm{A}$, soit en raison d'une recombinaison génétique entre les sous-types $\mathrm{HA}$, soit en raison de multiples phénomènes mutationnels qui donnent naissance à un nouveau virus possédant un potentiel pandémique dans une population mondiale naïve d'un point de vue immunologique.

\section{Les manifestations cliniques et les complications de la} grippe chez l'enfant

Les manifestations cliniques de l'infection par le virus de la grippe A sont très variables et la gravité de la maladie dépend du niveau de la mémoire immunitaire avant l'infection pour des virus antigéniquement proches. Après une période d'incubation de 1 à 4 jours, la grippe classique se manifeste par de fortes poussées de fièvre, des maux de tête, la toux, des douleurs musculaires et des maux de gorge [82, 86, 90, 91]. Des symptômes gastrointestinaux peuvent également apparaître, plus souvent chez les enfants que chez les adultes. La grippe peut induire des complications graves telles que la bronchite hémorragique, la pneumonie, le sepsis, les crises fébriles et peut même conduire à la mort $[82,86,93]$. D'un point de vue clinique, la grippe se manifeste différemment chez les enfants en fonction de leur âge [82]. Chez les nourrissons et les jeunes enfants, seule une forte fièvre peut être observée, sans autre symptôme, alors que l'évolution de la 
maladie est souvent similaire chez les enfants plus âgés et les adultes. Les infections grippales chez les enfants, en particulier chez les très jeunes enfants, passent donc souvent inaperçues lors des consultations médicales [79, 82, 90, 91, 94]. Par exemple, les premiers symptômes des jeunes enfants infectés par le virus de la grippe peuvent ressembler à ceux d'un sepsis d'origine bactérienne accompagné de fortes fièvres $[90,91]$.

Lotite moyenne aiguë est la complication la plus courante de la grippe chez les enfants et est observée dans 50 à $60 \%$ des cas $[79,91,95]$. En raison de son association à une maladie fébrile, à la pneumonie bactérienne ou à l'otite moyenne interne, la grippe pédiatrique est souvent traitée à tort par des antibiotiques [53, 96, 97]. Les complications grippales les plus graves observées chez l'enfant sont pulmonaires, à savoir la bronchiolite, la pneumonie virale primaire, la pneumonie bactérienne secondaire, le sepsis et les complications neurologiques $[79,81,90,93$, 98, 99-102].

La pneumonie bactérienne secondaire chez l'enfant augmente très significativement le risque de mortalité et est souvent causée par $S$. aureus, bien que la pneumonie à pneumocoque sévère soit également liée à une précédente infection par le virus de la grippe $\mathrm{A}(\mathrm{H} 1 \mathrm{~N} 1)$ [83, 103]. Il se peut que la grippe et le $S$. aureus interagissent de manière spécifique et synergique et augmentent le risque de contracter des co-infections grippe-S. aureus [104]. De plus, une étude rétrospective récente d'échantillons de patients et les données concernant la grave pandémie de 1918 suggèrent que la grande majorité des décès étaient due à une infection bactérienne secondaire par des espèces bactériennes courantes des voies respiratoires supérieures, dont le pouvoir pathogène aurait été renforcé par le virus de la grippe [105]. Au cours des cinq dernières années, on a observé une augmentation significative, à la fois chez l'enfant et chez l'adulte, de l'incidence de pneumonie bactérienne associée à la grippe et causée par un $S$. aureus ayant développé une résistance à la méthicilline $[93,104,106]$. Ainsi, durant les trois saisons grippales 2004-2007, le taux de mortalité associée à la grippe était faible chez l'enfant, mais le taux de co-infection grippe-S. aureus a été multiplié par cinq (de 6 à 34\%), le $S$. aureus résistant à la méthicilline étant impliqué dans $64 \%$ des cas [107].

Les convulsions fébriles sont les complications neurologiques les plus courantes de la grippe chez la population pédiatrique, les enfants âgés de 2 à 4 ans étant les plus vulnérables [81, 90, 99, 101, 102]. L'incidence des convulsions fébriles chez les enfants hospitalisés infectés par la grippe varie de 6 à $20 \%[90,99,102]$. Bien que moins cou- rante, l'encéphalite aigüe est une autre complication grave observée chez les enfants affectés par le virus de la grippe $[100,101]$.

\section{L'impact de la réémergence de l'épidémie de grippe} chez les enfants

$\mathrm{Au}$ cours des épidémies annuelles, le rassemblement d'enfants sensibles dans les écoles fournit un terrain idéal à la transmission de la grippe [108]. Son taux de contamination, variant de 15 à $42 \%$, est le plus élevé parmi les enfants d'âge scolaire ou préscolaire. La fréquentation des crèches et des écoles est un facteur favorisant le risque d'infection [77-79, 81, 85]. Les enfants d'âge scolaire sont souvent victimes d'un pic de prévalence dans la première phase de l'épidémie, suivis par des cas chez les nourrissons et les adultes. Les taux d'infection de la grippe peuvent être très élevés chez les nourrissons et la maladie a été observée chez un tiers des nourrissons suivis, de la naissance à un an $[76,97]$. Les nourrissons et jeunes enfants non vaccinés sont davantage exposés au risque d'infection car ils n'ont jamais été précédemment au contact du virus et n'ont donc pas développé de mémoire immunitaire contre ce virus [53].

Bien que la plupart des épisodes de grippe chez l'enfant résultent en une guérison spontanée, des enfants de tout âge peuvent être victimes de graves complications nécessitant une hospitalisation, des soins intensifs et dans certains cas, une assistance respiratoire. L'incidence de complications graves et la mortalité sont plus importantes chez les enfants de moins de deux ans et les enfants ayant des pathologies sous-jacentes [79, 90, 91, 93, 98, 109]. De même, les femmes enceintes, et par conséquent le(s) foetus qu'elles portent, sont également des populations vulnérables [82, 93, 110-112]. Par ailleurs, chez l'enfant, les maladies cardiaques et les maladies neurologiques et neuromusculaires sont des facteurs de risque spécifiques de complications de la grippe $[53,98,113,114]$.

Les taux excessifs de consultation et d'hospitalisation d'enfants, liées aux épidémies de grippe ou à la confirmation de l'infection grippale par des tests de laboratoire, ont fait l'objet de nombreuses études [79, 82, 84, 91, 94, 96, 98, 115-118]. Ces taux sont plus élevés chez les enfants présentant des pathologies sous-jacentes, mais ils restent importants chez les enfants en bonne santé et, dans les 2 cas, sont inversement corrélé à l'âge $[82,84,91,93,96,98$, $115,118]$.

D'après les études de Neuzil et al. $[79,96]$, chaque année, 8 à 15\% des enfants en bonne santé âgés de moins de cinq ans consultent pour des complications grippales. Parmis les consultations supplémentaires hivernales, 
$35 \%$ concernent la grippe chez les enfants de 1 à 3 ans [96]. Des études américaines et françaises ont montré que durant la saison grippale, les infections de grippe confirmées par des tests en laboratoire étaient responsables de $28,8 \%$ de toutes les visites aux urgences pédiatriques pour les enfants de moins de 5 ans et de 33\% des visites pour les nourrissons âgés de 0 à 11 mois [94, 119].

Les enfants sont plus susceptibles que les adultes d'être victimes de grippes saisonnières graves nécessitant l'hospitalisation [90, 91]. Une étude comparative entre des enfants de moins de 14 ans et des sujets âgés de 15 à 64 ans a montré que, pendant une épidémie grippale, les enfants avaient 3 à 5 fois plus de risques d'être hospitalisés pour des complications grippales [84], principalement pour des infections aiguës des voies respiratoires inférieures (bronchite et pneumonie). Les enfants de moins de 2 ans et les personnes âgées sont les populations les plus à risque d'être hospitalisées [77, 85, 91, 96, 115, 116, 120]. Des pathologies sous-jacentes telles qu'un sepsis ou un asthme peuvent être des facteurs aggravant $[84,121]$. Des études sur l'incidence d'hospitalisation chez les enfants grippés (confirmé par des tests de laboratoire), ont montré que 77 à $80 \%$ de ces enfants avaient moins de 5 ans et 25 à $27 \%$ avaient moins de 6 mois $[98,102]$.

Les cas de grippe mortelle chez l'enfant sont rares [81, $90,91]$, bien que cette mortalité soit très variable: pendant la saison 2003-2004, les décès associés à la grippe furent trois fois plus nombreux que les deux saisons suivantes [122]. La majorité de ces décès a concerné les enfants de moins de 5 ans, avec les taux de mortalité les plus élevés pour les nourrissons de moins de 6 mois. Curieusement, malgré le fait que les enfants à haut risque développent le plus souvent les complications de la grippe, la majorité de décès liée à la grippe a été observé chez les enfants en bonne santé et de tous les âges, et non $[122,123]$.

\section{La vaccination contre la grippe}

L'immunisation de masse des enfants scolarisés serait un bon moyen pour prévenir la propagation de l'infection grippale dans la population [124-127]. Elle s'est notamment révélée plus efficace que la vaccination systématique des personnes âgées et des sujets à risque pour atténuer les impacts de la grippe dans ces populations [127].

La prise de conscience croissante de l'impact excessif et grave de la grippe chez les enfants a conduit à une évolution des recommandations concernant la vaccination. Ces dix dernières années et contrairement aux préconisations antérieures, le comité consultatif sur les pratiques d'immunisation (Advisory Committee on Immunisation Practices, ACIP) recommande une couverture vaccinale totale des enfants âgés de 6 mois à 18 ans en bonne santé $[90,128,129]$. La vaccination des personnes d'un même foyer en contact avec les enfants est également recommandée, car considérée importante dans le cadre d'une stratégie de prévention $[85,122,129]$. C'est notamment le cas des personnes en contact avec des enfants de moins de 6 mois, exposés à une morbidité et à une mortalité grippales élevées et pour lesquels il n'existe pas encore de vaccin. Il est également recommandé aux femmes enceintes de se faire vacciner lors de leur troisième trimestre de grossesse de façon à transmettre aux nouveaux nés une protection humorale efficace et ainsi limiter les complications grippales graves [82].

Malheureusement, malgré ces nouvelles recommandations, la couverture vaccinale des enfants demeure outrageusement faible [52, 123]: seulement $6 \%$ des enfants ayant succombé à des complications grippales pendant les saisons 2004-2007 avaient été vaccinés [107]. Les enfants représentent effectivement une population vulnérable: leur immunisation contre la grippe ou contre toute autre maladie pour laquelle il existe un vaccin dépend non seulement des organismes de santé publique chargés de promouvoir et de distribuer les vacccins, mais aussi des parents ou tuteurs pour réclamer ces vaccins et des médecins pour les recommander. Cette faible couverture vaccinale grippale peut s'expliquer en partie par la périodicité de cette vaccination (annuelle) et par le fait que dans l'esprit du grand public, la grippe n'entraîne pas de complications graves [85]. Ainsi, une étude réalisée auprès de familles ayant des enfants atteints de maladies chroniques et fréquentant des cliniques spécialisées en pédiatrie, a révélé que parmi les parents d'enfants non vaccinés (52\% des enfants), $61 \%$ d'entre eux pensaient que le vaccin lui-même pouvait causer la grippe, $54 \%$ émettaient des doutes quant à son innocuité et $30 \%$ pensaient que le vaccin n'était pas efficace [130].

\section{Impact d'une pandémie de grippe émergente sur les enfants}

Les archives et comptes-rendus historiques indiquent que les nourrissons, les jeunes enfants et les adolescents sont des sous-populations touchées de manière spécifique par les pandémies de grippe [86]. En effet, durant la première pandémie répertoriée de 1510 , on avait enregistré une faible mortalité, limitée aux jeunes enfants [131]. En général, les jeunes enfants et les nourrissons sont plus sensibles aux infections causées par les virus de grippes pandémiques. Ceci s'explique en partie par le fait qu'ils 
représentent une population naïve d'un point de vue immunologique, contrairement à d'autres personnes plus âgés qui ont pu être précédemment exposés à des virus ayant généré une réaction antigénique croisée [52]. La pandémie de grippe russe H1N1 de 1977, limitée à une population très jeune, illustre ce phénomène [132-134]. La morbidité due à cette grippe fut presque exclusivement limitée à des personnes de moins de 25 ans. On suppose que la résistance des populations plus âgées était due à l'immunité qu'ils avaient acquise lors de précédentes expositions à des sous-types de virus H1N1, entre 1946 et 1957, c'est-à-dire des virus partageant les mêmes caractéristiques antigéniques [132-134].

Trois virus de la grippe ont causé d'importantes pandémies au cours du vingtième siècle. La plus meurtrière des trois, la grippe espagnole H1N1 de 1918, fut responsable de la mort de 50 millions de personnes. En comparaison, le virus asiatique $\mathrm{H} 2 \mathrm{~N} 2$ en 1957 et le virus H3N2 de Hong Kong en 1968 ont respectivement causé la mort de deux millions et un million de personnes. Ces pandémies étaient le résultat de l'adaptation à l'homme d'un nouveau sous-type de l'HA d'origine aviaire ou porcine, ayant entraîné un «antigenic shift». On pense que le virus $\mathrm{H} 1 \mathrm{~N} 1$ de 1918 résulte de l'accumulation de mutations d'un virus grippal d'origine aviaire ou porcine, lui permettant alors de se répliquer et de se transmettre chez l'homme [92, 131, 134-136]. En revanche, les virus $\mathrm{H} 2 \mathrm{~N} 2$ et $\mathrm{H} 3 \mathrm{~N} 3$ respectivement responsables des pandémies de 1957 et 1968, ont émergé suite à un réassortiment entre des segments de gènes provenant de virus humains et aviaires. Chose intéressante, alors que la morbidité et la mortalité étaient élevées parmi les nourrissons et jeunes enfants au cours des trois pandémies, durant la pandémie de 1918, les enfants âgés de 4 à 13 ans présentaient les taux d'infection les plus élevés mais les taux de mortalité liés à l'âge les plus faibles comparés aux autres tranches d'age $[52,105,135]$. Ce phénomène reste inexpliqué mais les taux de mortalité observés étaient similaires à ceux décrits pour les autres maladies infectieuses, à savoir les oreillons, la rougeole, la varicelle et le syndrome respiratoire aigu sévère $[52,137,138]$. Ce phénomène pourrait également être lié à la modulation de la réponse immunitaire pédiatrique, avec un équilibre entre les réponses immunitaires qui protègent contre un pathogène infectieux et celles qui induisent une inflammation excessive et une altération des tissus [52].

Une pandémie grippale survient à trois conditions: (1) l'émergence d'un virus auquel la population est naïve d'un point de vue immunologique, (2) ce virus peut se répliquer et causer une maladie chez l'homme, (3) il se transmet facilement d'homme à homme. Jusqu'à récemment, le virus aviaire $\mathrm{H} 5 \mathrm{~N} 1$ était le virus grippal à potentiel pandémique le plus inquiétant car il remplissait les deux premières conditions. Cependant, au printemps dernier, un nouveau virus de la grippe A d'origine porcine, le virus A(H1N1), est apparu au Mexique et, en l'espace de quelques mois, était reconnu comme induisant une grippe pandémique à l'échelle internationale [92]. La pandémie de grippe $\mathrm{A}(\mathrm{H} 1 \mathrm{~N} 1)$ et la menace pandémique du virus aviaire H5N1 ont mobilisé l'attention non seulement sur la nécessité de se préparer à une pandémie grippale grave, associée à une morbidité et à une mortalité importantes, mais aussi sur les défis spécifiques à relever pour assurer les soins des populations les plus jeunes [123, 139-145]. Dans la section suivante, nous examinons les conséquences éventuelles d'une pandémie grippale virulente sur le bien-être des nourrissons et des enfants et nous abordons également les problèmes qui pourraient devenir un véritable défi dans les pays en développement. Lorsque cela sera justifié, nous illustrerons nos propos par les expériences récentes observées avec le virus aviaire de la grippe $\mathrm{H} 5 \mathrm{~N} 1$, très pathogène, et le nouveau virus de la grippe $\mathrm{A}(\mathrm{H} 1 \mathrm{~N} 1)$.

Dans le cas d'une large pandémie grippale, les enfants seront probablement parmi les premiers touchés, victimes des taux d'infection les plus élevés en raison des facteurs de risque auxquels ils sont exposés: naïveté immunitaire et regroupement dans les écoles et les crèches. On estime que lors d'une pandémie, les enfants pourraient représenter jusqu'à $40 \%$ des cas de grippe aux États-Unis et que les nourrissons et les jeunes enfants présenteraient des taux de morbidité et de mortalité très élevés et supérieurs à ceux observés durant les périodes interpandémiques $[143,144,146]$. Des études épidémiologiques portant sur les infections par les virus humains $\mathrm{H} 5 \mathrm{~N} 1$ et $\mathrm{A}(\mathrm{H} 1 \mathrm{~N} 1)$ vont dans le même sens, indiquant des taux d'infection particulièrement élevés chez les enfants, avec les complications les plus graves et la mortalité la plus importante chez les enfants [112-114, 147-156].

\section{Le virus de la grippe aviaire H5N1}

Les infections chez l'homme dues au virus H5N1 ont fait leurs premières apparitions à Hong Kong en 1997; elles seraient la conséquence de «débordements» d'une épizootie observée chez les volailles [131, 149]. Les taux de mortalité associés à la grippe $\mathrm{H} 5 \mathrm{~N} 1$ sont supérieurs à $50 \%$, la mort touchant le plus souvent des enfants jusqu'alors en bonne santé, et développant comme complication grippale un syndrome de détresse respiratoire 
aiguë $[147-150,156]$. On estime que si le virus H5N1 devait muter et ainsi acquérir la capacité de se transmettre efficacement d'homme à homme tout en maintenant son niveau actuel de virulence, il causerait une pandémie à forte mortalité (plusieurs millions de victimes) [141, 157]. De nombreuses études sur la répartition des cas de grippe H5N1 en fonction de l'âge ont montré que cette maladie touche principalement les enfants et jeunes adultes alors que les adultes plus âgés et les personnes âgées sont plutôt épargnés [114, 148-150]. Le taux d'infection élevé chez les enfants est probablement associé au fait que dans les pays où la grippe aviaire $\mathrm{H} 5 \mathrm{~N} 1$ est endémique chez les volailles, c'est traditionnellement le rôle des enfants de s'occuper des volailles $[144,150]$. De plus, la régularité de la répartition des cas de grippe $\mathrm{H} 5 \mathrm{~N} 1$ en fonction de l'âge, quelles que soient les sociétés et les cultures, pourrait également s'expliquer par un modèle récurrent d'immunité contre la grippe aviaire $\mathrm{A}(\mathrm{H} 5 \mathrm{~N} 1)$, très répandue géographiquement, chez les personnes nées avant 1969 [114].

\section{La grippe porcine $A(H 1 N 1)$}

La nouvelle grippe $\mathrm{A}(\mathrm{H} 1 \mathrm{~N} 1)$ qui émergea au Mexique au cours du printemps 2009 semble provenir d'un réassortiment de 2 souches de la grippe A d'origine porcine: une souche d'Amérique du Nord dérivée du virus humain H1N1 de 1918, et une souche eurasienne [92, 158]. Le temps qu'elle soit identifiée au Mexique en avril 2009, les voyageurs empruntant les compagnies aériennes internationales avaient déjà répandu le virus dans le monde entier. Ainsi, malgré les efforts réalisés pour contenir le virus dans sa région d'origine, l'Organisation Mondiale de la Santé a rapporté dès le 25 mai que le virus avait infecté au total 12515 individus répartis dans 43 pays $[159,160]$. Le premier cas d'infection de la grippe $\mathrm{A}(\mathrm{H} 1 \mathrm{~N} 1)$ aux États-Unis a été identifié le 15 avril 2009 et, dès le 5 mai, on comptait déjà 642 cas confirmés, avec une majorité (60\%) touchant des patients âgés de moins de 18 ans [151]. Une répartition similaire fut observée dans les cas mexicains rapportés entre le $1^{\text {er }}$ mars et le 29 mai 2009, avec $42 \%$ des infections survenant chez des enfants de moins de 15 ans [152]. Les épidémies de grippe A(H1N1) associées à la fréquentation scolaire furent rapportées très tôt dans l'évolution de la pandémie, et ce dans de nombreux pays tels qu'aux États-Unis, en Australie, au RoyaumeUni et au Japon. La fermeture des écoles fut alors décidée pour limiter la propagation de la maladie [161-164]. L'analyse des données de patients américains et européens révéla deux populations particulièrement touchées par le virus de la grippe $\mathrm{A}(\mathrm{H} 1 \mathrm{N1})$ : les jeunes adultes exposés

Nouvelles infections émergentes:

Impact sur la santé de l'enfant lors de voyages, répandant par la suite à leur tour le virus au niveau mondial, et les enfants d'âge scolaire, jouant un rôle clé dans l'amplification du virus [113, 151]. La répartition des cas par classe d'âge observée en Europe début juin reflétait clairement la composition de ces deux populations, l'âge moyen des cas importés étant de 25 ans, celui des cas non importés étant de 13 ans [113]. Ces données soulignent la vulnérabilité extrême des enfants à l'infection par un nouveau virus de grippe pandémique émergente.

Bien qu'une faible morbidité et qu'une faible mortalité soient associées à la grippe $\mathrm{A}(\mathrm{H} 1 \mathrm{~N} 1)$, les enfants représentent une population vulnérable. Des complications neurologiques telles que des attaques cérébrales et des troubles de conscience ont été rapportées chez des enfants âgés de 7 à 17 ans [112]. De plus, tout comme pour la grippe épidémique, une proportion significative des enfants atteints de la grippe $\mathrm{A}(\mathrm{H} 1 \mathrm{~N} 1)$ manifestent des symptômes gastro-intestinaux, phénomène qui risque de retarder le diagnostique de l'infection [113, 161, 162]. Fin juillet 2009, les centres de prévention et de contrôle des maladies (Centers for Disease Control, CDC) ont rapporté que durant la saison grippale de 2008-2009, un total de 97 décès pédiatriques directement ou indirectement liés à la grippe avait été enregistré, avec un second pic de mortalité, peu commun, à la fin de l'épidémie saisonnière habituelle [153], attribué à la grippe $\mathrm{A}(\mathrm{H} 1 \mathrm{~N} 1)$. Par ailleurs, les femmes enceintes infectées par la grippe $\mathrm{A}(\mathrm{H} 1 \mathrm{~N} 1)$ représentent également une population à risque de développer des complications graves, pouvant être fatales pour ellesmêmes ou leurs foetus ou pouvant entraîner un avortement $[154,165]$.

Une étude récente de 2155 cas de grippe (confirmés par des tests de laboratoire) compliqués d'une pneumonie sévère, observés au Mexique entre le 24 mars et le 29 avril 2009, a montré une réorientation marquée dans la répartition par classe d'âge de la morbidité et de la mortalité. En effet, $71 \%$ de la morbidité et $87 \%$ de la mortalité étaient observées chez les patients âgés de 5 à 59 ans [155]. Fait particulièrement remarquable, le nombre de décès de pneumonie sévère chez les enfants entre 5 et 9 ans, 10 et 14 ans et 15 et 19 ans a été presque multiplié par cinq [155]. Une grande proportion de ces cas était probablement due à l'infection par le virus $\mathrm{A}(\mathrm{H} 1 \mathrm{~N} 1)$ [155]. Il semblerait que cette évolution de la répartition par classe d'âge soit liée à une protection relative des personnes exposées aux souches H1N1 au cours de leur enfance, avant la pandémie de 1957, justifiant la nécessité de focaliser les efforts de prévention sur les populations plus jeunes [155]. 
Problèmes potentiels face à une pandémie de grippe $A(H 1 N 1)$ virulente

Au moment de la rédaction de cet article, la morbidité et la mortalité liées à la grippe $\mathrm{A}(\mathrm{H} 1 \mathrm{~N} 1)$ étaient relativement faibles et similaires à celles observées lors de périodes interpandémiques. Cependant, ces taux pourraient augmenter de manière drastique si le virus devait subir des mutations dont la conséquence serait une augmentation de sa virulence. Face à une large pandémie de grippe virulente, les défis seraient multiples, tels que s'occuper à la fois des enfants malades et de ceux en bonne santé [123, 139-141, 143-145, 166]. Répondre aux besoins des patients pédiatriques lors des pics pandémiques serait un veritable défi à relever en termes de ressources à la fois matérielles, et en personnel médical dans les pays industrialisés, et ne ferait qu'accabler davantage les pays en voie de développement dont les ressources humaines, matérielles et financières sont déjà extrêmement limitées et surexploitées [123, 139, 143-146, 166]. Les cliniques et les hôpitaux devraient alors augmenter leur capacité d'accueil dans les services de pédiatrie comme, par exemple, le nombre de lits et le nombre de lits dans les unités de soins intensifs, mais également le nombre d'appareils d'assistance respiratoire conçus pour être utilisés chez les jeunes enfants et les nourrissons. Répondre aux besoins des enfants touchés par la grippe nécessiterait aussi une augmentation substantielle des effectifs de personnel médical qualifié et spécialisé dans l'administration de soins aux plus jeunes enfants. On a ainsi estimé qu'aux ÉtatsUnis, durant les pics épidémiques locaux, jusqu'à $20 \%$ du personnel médical ne serait pas disponible, eux-mêmes ou un membre de leur famille étant malades [144]. En résumé pendant une pandémie de grippe grave, il serait extrêmement compliqué et difficile d'augmenter la capacité de fonctionnement des hôpitaux et des cliniques pour être en mesure de s'occuper des patients pédiatriques infectés, et ces problèmes seraient encore plus difficiles à résoudre si une morbidité et une mortalité élevées touchaient les populations adultes.

Durant une pandémie grippale, beaucoup d'enfants malades ne seraient pas nécessairement hospitalisés mais ils auraient besoin de soins à domicile, administrés par leurs parents ou les personnes qui les gardent. De plus, les enfants en bonne santé seraient dépendents du personnel soignant pour bénéficier d'une thérapie préventive sous forme de vaccins ou de traitements prophylactiques à base d'antiviraux [123]. Donc, encore une fois, répondre dans les temps aux besoins cruciaux des enfants serait difficile et représenterait un défi énorme dans les situations où les parents et le personnel de garde seraient eux-mêmes trop malades pour s'occuper des enfants [123].

L'utilisation des vaccins et des antiviraux chez les enfants posent également des problèmes, tels que la définition de la dose appropriée, les effets secondaires et l'observance. Certaines de ces difficultés sont illustrées par l'utilisation de l'antiviral oseltamivir (Tamiflu ${ }^{\circledR}$ ), inhibiteur de la NA, dans le cadre de la pandémie actuelle de grippe $\mathrm{A}(\mathrm{H} 1 \mathrm{~N} 1)[139,162,167,168]$. Jusqu'à récemment, l'oseltamivir était recommandé pour le traitement et la prévention de la grippe uniquement chez les adultes et les enfants de plus de 1 an. Cependant, en raison de l'émergence de la grippe $\mathrm{A}(\mathrm{H} 1 \mathrm{N1}$ ), la FDA (Food and Drug Administration) a autorisé officiellement, en cas d'urgence, l'utilisation de l'oseltamivir pour le traitement des enfants de moins de 1 an et en tant que chimioprophylaxie chez les nourrissons de moins de 3 mois [169]. Des problèmes importants concernant l'observance du traitement et les effets secondaires sont toutefois apparus. Une étude conduite dans des écoles de Londres comptant des cas confirmés de grippe $\mathrm{A}(\mathrm{H} 1 \mathrm{~N} 1)$ a montré que parmi les élèves à qui l'on a proposé de suivre un traitement prophylactique à l'oseltamivir, seuls $89 \%$ d'entre eux l'ont suivi, parmi lesquels seulement $48 \%$ des élèves du primaire et $76 \%$ du secondaire ont poursuivi leur traitement jusqu'au bout [167]. De plus, 53\% des élèves ont rapporté des effets secondaires à la prise d'oseltamivir, essentiellement des troubles gastro-intestinaux (40\%). Ceci contraste avec une étude menée chez des étudiants japonais pour qui le traitement par oseltamivir a été bien toléré et sans effets secondaires [162]. Il est également nécessaire de noter qu'avant avril 2009, il n'y avait aucune donnée quant à l'efficacité des agents antiviraux dans le traitement et la prévention del'infection par le virus de la grippe $\mathrm{A}(\mathrm{H} 1 \mathrm{~N} 1)$ chez l'homme et aucun vaccin n'existait. De plus, il est probable que les vaccins contre le virus de la grippe $\mathrm{A}(\mathrm{H} 1 \mathrm{~N} 1)$ et les antiviraux doivent être utilisés à des dosages différents selon si le traitement est destiné à un enfant ou à un adulte $[123,139,168]$.

La fermeture des écoles est une stratégie potentielle importante pour limiter la transmisson de la maladie lors d'une pandémie de grippe et, comme indiqué précédemment, le recours à cette stratégie a déjà eu lieu pour tenter de limiter la propagation du virus de la grippe $\mathrm{A}(\mathrm{H} 1 \mathrm{~N} 1)$ [161-164]. La fermeture des écoles et des crèches pendant une période prolongée pourrait avoir des conséquences importantes chez les enfants, à différents niveaux. En effet, ces institutions sont non seulement chargées de l'instruction des enfants mais elles permettent également d'établir un réseau social dans lequel les enfants peuvent 
grandir, apprendre et se développer, à une période de leur vie où ils sont vulnérables $[95,123,170]$. De plus, pour beaucoup d'entre eux, en particulier ceux issus des milieux socioéconomiques les plus défavorisés, interrompre l'école peut également signifier ne plus avoir accès à leur principale source de nutrition dont ils bénéficient à travers les programmes alimentaires scolaires [123]. Les répercussions psychologiques dues non seulement à l'interruption de la routine journalière mais également à la maladie ou à la mort d'un ami ou d'un membre de la famille ne feraient que se rajouter au très lourd impact d'une pandémie de grippe sur ces enfants [123].

Bien que les pays industrialisés seraient face à de très grandes difficultés pour administrer les soins nécessaires aux enfants en cas de pandémie grippale grave, l'énorme fardeau que représente la pandémie aurait sans nul doute des effets catastrophiques dans les pays en voie de développement, et les enfants de ces régions seraient d'autant plus vulnérables et exposés aux risques de morbidité et de mortalité liées à la grippe $[140,145,146,171]$. En se basant sur des preuves empiriques rassemblées à partir de recueils de données de survie lors de la pandémie de grippe de 1918, il a été estimé que si une pandémie de virulence similaire devait se développer de nos jours, la mortalité liée à cette pandémie serait multipliée par 30 et serait très largement corrélée aux ressources économiques individuelles [146]. De plus, parmi les 62 millions de décès hypothétiques, $28 \%$ toucheraient des enfants de moins de 15 ans et $96 \%$ surviendraient dans des pays en voie de développement. Proportionnellement, les décès frapperaient probablement l'Afrique subsaharienne plus que toute autre région du monde [146].

Par ailleurs, dans les pays en voie de développement, la prévalence toujours élevée d'autres maladies infectieuses telles que le VIH, le paludisme, la $\mathrm{Tb}$, les maladies diarrhéiques et respiratoires infantiles et la malnutrition sont des facteurs aggravants qui rendraient les enfants encore plus vulnérables lors d'une pandémie grippale grave [82, 140, 145, 146, 157, 172]. Par exemple, les données recueillies lors de pandémies grippales antérieures suggèrent que le paludisme endémique est un facteur de risque de mortalité pendant les pandémies [157]. De plus, les enfants séropositifs avec un système immunitaire affaibli ont un risque plus élevé d'hospitalisation (suite à des infections des voies respiratoires inférieures) et de mortalité grippale [146, 157, 173, 174]. Une pandémie grippale grave pourrait avoir également d'autres conséquences dramatiques pour les enfants, telle que l'inévitable réorientation des ressources destinées à la santé publique et soins médicaux pour traiter la grippe. Cette réorientation des ressources pourrait sérieusement compromettre les programmes de santé existants et exacerber les problèmes de santé publique pré-existants touchant directement ou indirectement les enfants. Parmi les programmes et actions compromis par une réorientation des priorités en faveur de la pandémie grippale, on peut citer ceux visant les maladies couvertes par une vaccination et les maladies infectieuses telles que le VIH, le paludisme, la $\mathrm{Tb}$, la pneumonie et les diarrhées infectieuses de l'enfant [145].

Les défis auxquels seraient confrontés les pays en voie de développement en cas de pandémie grippale peuvent être illustrés par les difficultés qu'ont dû surmonter les pays d'Afrique subsaharienne pour prévenir la propagation du virus $\mathrm{H} 5 \mathrm{~N} 1 \mathrm{chez}$ les volailles. Le virus aviaire H5N1 est tout d'abord apparu sur ce continent lors d'une épidémie parmi des volailles au Nigéria en janvier 2006 [140]. La prise de conscience immédiate du potentiel dévastateur de ce virus a conduit à une réorientation soudaine et importante des priorités de santé publique afin d'essayer de contenir l'épidémie. Malgré les efforts concertés des organisations de santé nationales et internationales, le virus aviaire $\mathrm{H} 5 \mathrm{~N} 1$ s'est rapidement propagé dans d'autres pays subsahariens, entraînant de sévères conséquences nutritionnelles et économiques, principalement dans les régions rurales et semi-urbaines du Nigéria [140]. La propagation du virus aviaire H5N1 dans cette région a donc non seulement montré les difficultés auxquelles les systèmes de santé publique, déjà bien éprouvés en Afrique, sont confrontés pour répondre à une crise de pandémie grippale, mais elle a aussi mis en évidence le coût qu'une telle crise représenterait pour la prise en charge des problèmes de santé existants [140]. Les problèmes quant au prix à payer pour la réorientation des priorités en faveur de la pandémie grippale $\mathrm{A}(\mathrm{H} 1 \mathrm{~N} 1)$ et au détriment des problèmes de santé existants dans les pays en voie de développement ont déjà été soulevés [175].

\section{Conclusions}

Au cours du $20^{\text {ème }}$ siècle et maintenant au $21^{\text {ème }}$ siècle, la grippe est devenue l'un des prototypes de maladies infectieuses réémergentes. Depuis plusieurs années, nous nous préparions à une pandémie grippale causée par une éventuelle mutation du virus de la grippe aviaire $\mathrm{H} 5 \mathrm{~N} 1$ facilitant sa propagation d'homme à homme. Cependant, la grippe aviaire n'apparait pas (encore) comme une menace majeure pour l'homme, mais tous les efforts visant à se préparer à une pandémie couvrant une zone géogra- 
phique très étendue n'ont pas été vains. L'émergence soudaine et la propagation rapide de la grippe porcine $\mathrm{A}(\mathrm{H} 1 \mathrm{~N} 1)$ a entraîné une pandémie mondiale qui a déjà de profondes répercussions chez les enfants et les adultes. Les lieux où les individus sont en contact rapproché tels que les écoles et les crèches, ainsi que les moyens de trans- ports modernes et les voyages internationaux ont facilité la propagation de cette nouvelle souche de la grippe. La grippe porcine est donc un excellent exemple pour illustrer comment l'interaction de facteurs environnementaux et humains entraîne l'émergence ou la réémergence de maladies infectieuses.

\section{Bibliographie}

1 Jones KE, Patel NG, Levy MA, et al: Global trends in emerging infectious diseases. Nature 2008;451:990-993.

$\longrightarrow 2$ Morens DM, Folkers GK, Fauci AS: Emerging infections: a perpetual challenge. Lancet Infect Dis 2008;8:710-719.

-3 Binder S, Levitt AM, Sacks JJ, Hughes JM: Emerging infectious diseases: public health issues for the 21st century. Science 1999;284: 1311-1313.

4 Yewhalaw D, Legesse W, Van Bortel W, et al: Malaria and water resource development: the case of Gilgel-Gibe hydroelectric dam in Ethiopia. Malar J 2009;8:21.

5 Matthys B, Vounatsou P, Raso G, et al: Urban farming and malaria risk factors in a medium-sized town in Cote d'Ivoire. Am J Trop Med Hyg 2006;75:1223-1231.

6 Li YS, Raso G, Zhao ZY, et al: Large water management projects and schistosomiasis control, Dongting Lake region, China. Emerg Infect Dis 2007;13:973-979.

$>7$ Oladejo SO, Ofoezie IE: Unabated schistosomiasis transmission in Erinle River Dam, Osun State, Nigeria: evidence of neglect of environmental effects of development projects. Trop Med Int Health 2006;11:843-850.

$\checkmark 8$ Watson JT, Gayer M, Connolly MA: Epidemics after natural disasters. Emerg Infect Dis 2007;13:1-5.

9 Ivers LC, Ryan ET: Infectious diseases of severe weather-related and flood-related natural disasters. Curr Opin Infect Dis 2006;19: 408-414.

10 Ligon BL: Infectious diseases that pose specific challenges after natural disasters: a review. Semin Pediatr Infect Dis 2006;17:3645.

11 Jeremijenko A, McLaws ML, Kosasih H: A tsunami related tetanus epidemic in Aceh, Indonesia. Asia Pac J Public Health 2007;19: 40-44.

12 Karmakar S, Rathore AS, Kadri SM, et al: Post-earthquake outbreak of rotavirus gastroenteritis in Kashmir (India): an epidemiological analysis. Public Health 2008;122: 981-989.

13 Hjelle B, Glass GE: Outbreak of hantavirus infection in the Four Corners region of the United States in the wake of the 1997-1998 El Nino-southern oscillation. J Infect Dis 2000; 181:1569-1573.
14 Costello A, Abbas M, Allen A, et al: Managing the health effects of climate change: Lancet and University College London Institute for Global Health Commission. Lancet 2009; 373:1693-1733.

15 Morens DM, Folkers GK, Fauci AS: The challenge of emerging and re-emerging infectious diseases. Nature 2004;430:242-249.

16 Ropelewski CF, Halpert MS: Global and regional scale precipitation patterns associated with the El Niño Southern Oscillation. Mon Wea Rev 1987;115:1606-1626.

17 Bouma MJ, Dye C: Cycles of malaria associated with El Nino in Venezuela. JAMA 1997; 278:1772-1774.

18 Viboud C, Pakdaman K, Boelle PY, et al: Association of influenza epidemics with global climate variability. Eur J Epidemiol 2004;19: 1055-1059.

19 Bouma MJ, van der Kaay HJ: The El Nino Southern Oscillation and the historic malaria epidemics on the Indian subcontinent and Sri Lanka: an early warning system for future epidemics? Trop Med Int Health 1996;1:8696.

20 Hales S, de Wet N, Maindonald J, Woodward A: Potential effect of population and climate changes on global distribution of dengue fever: an empirical model. Lancet 2002;360: 830-834.

21 Nicholls N: El nino-southern oscillation and vector-borne disease. Lancet 1993;342: 1284-1285.

22 Wu PC, Lay JG, Guo HR, et al: Higher temperature and urbanization affect the spatial patterns of dengue fever transmission in subtropical Taiwan. Sci Total Environ 2009;407: 2224-2233.

23 Spielman A: The emergence of Lyme disease and human babesiosis in a changing environment. Ann NY Acad Sci 1994;740:146156.

24 West Nile virus activity - United States, 2007. MMWR Morb Mortal Wkly Rep 2008; 57:720-723.

25 Gubler DJ: The continuing spread of West Nile virus in the western hemisphere. Clin Infect Dis 2007;45:1039-1046.

26 Stone R: The mouse-pinon nut connection. Science 1993;262:833.
27 Whittam TS, Wolfe ML, Wachsmuth IK, et al: Clonal relationships among Escherichia coli strains that cause hemorrhagic colitis and infantile diarrhea. Infect Immun 1993; 61:1619-1629.

28 Griffin PM, Tauxe RV: The epidemiology of infections caused by Escherichia coli O157:H7, other enterohemorrhagic E. coli, and the associated hemolytic uremic syndrome. Epidemiol Rev 1991;13:60-98.

29 Ezzell C: Care for a dying continent. Sci Am 2000;282:96-105.

30 Halperin DT, Epstein H: Concurrent sexual partnerships help to explain Africa's high HIV prevalence: implications for prevention. Lancet 2004;364:4-6.

31 Tyndall MW, Currie S, Spittal S, et al: Intensive injection cocaine use as the primary risk factor in the Vancouver HIV-1 epidemic. AIDS 2003;17:887-893.

32 Alvar J, Jimenez M: Could infected drug-users be potential Leishmania infantum reservoirs? AIDS 1994;8:854.

33 Mercado R, Torres P, Munoz V, Apt W: Human infection by Pseudoterranova decipiens (Nematoda, Anisakidae) in Chile: report of seven cases. Mem Inst Oswaldo Cruz 2001; 96:653-655.

34 Lopez-Serrano MC, Gomez AA, Daschner A, et al: Gastroallergic anisakiasis: findings in 22 patients. J Gastroenterol Hepatol 2000; 15:503-506.

35 Turabelidze G, Lin M, Weiser T, Zhu BP. Communitywide outbreak of cryptosporidiosis in rural Missouri associated with attendance at child care centers. Arch Pediatr Adolesc Med 2007;161:878-883.

-36 Narita M, Fujitani S, Haake DA, Paterson DL: Leptospirosis after recreational exposure to water in the Yaeyama islands. Japan Am J Trop Med Hyg 2005;73:652-656.

37 Schwartz E, Kozarsky P, Wilson M, Cetron M: Schistosome infection among river rafters on Omo River, Ethiopia. J Travel Med 2005;12:3-8.

38 Sejvar J, Bancroft E, Winthrop K, et al: Leptospirosis in 'Eco-Challenge' athletes, Malaysian Borneo, 2000. Emerg Infect Dis 2003; 9:702-707.

-39 Simoes EA: RSV disease in the pediatric population: epidemiology, seasonal variability, and long-term outcomes. Manag Care 2008; $17: 3-6$. 
-40 Rossi GA, Medici MC, Arcangeletti MC, et al: Risk factors for severe RSV-induced lower respiratory tract infection over four consecutive epidemics. Eur J Pediatr 2007;166: 1267-1272.

-41 Principi N, Esposito S: Pediatric influenza prevention and control. Emerg Infect Dis 2004; 10:574-580.

-42 Lee MB, Greig JD: A review of enteric outbreaks in child care centers: effective infection control recommendations. J Environ Health 2008;71:24-32, 46.

-43 Lamunu M, Lutwama JJ, Kamugisha J, et al: Containing a haemorrhagic fever epidemic: the Ebola experience in Uganda (October 2000-January 2001). Int J Infect Dis 2004;8: 27-37.

44 Stuckler D, Basu S, McKee M, King L: Mass incarceration can explain population increases in TB and multidrug-resistant TB in European and central Asian countries. Proc Natl Acad Sci USA 2008;105:13280-13285.

-45 Pfyffer GE, Strassle A, van Gorkum T, et al: Multidrug-resistant tuberculosis in prison inmates, Azerbaijan. Emerg Infect Dis 2001; 7:855-861.

-46 Portaels F, Rigouts L, Bastian I: Addressing multidrug-resistant tuberculosis in penitentiary hospitals and in the general population of the former Soviet Union. Int J Tuberc Lung Dis 1999;3:582-588.

-47 Tuberculosis outbreaks in prison housing units for HIV-infected inmates - California, 1995-1996. MMWR Morb Mortal Wkly Rep 1999;48:79-82.

48 Neely F, Maguire H, Le Brun F, et al: High rate of transmission among contacts in large London outbreak of isoniazid mono-resistant tuberculosis. J Public Health (Oxf) 2009, Epub ahead of print.

-49 Fulop T, Pawelec G, Castle S, Loeb M: Immunosenescence and vaccination in nursing home residents. Clin Infect Dis 2009;48: 443-448.

-50 Nursing home outbreaks of invasive group A streptococcal infections - Illinois, Kansas, North Carolina, and Texas. MMWR Morb Mortal Wkly Rep 1990;39:577-579.

51 Grima A, Gatt A, Zahra G, Gambin A: Outbreak of norovirus infection in a nursing home for the elderly in Malta, NovemberDecember 2008. Euro Surveill 2009;14. pii:19103.

52 Ahmed R, Oldstone MB, Palese P: Protective immunity and susceptibility to infectious diseases: lessons from the 1918 influenza pandemic. Nat Immunol 2007;8:1188-1193.

53 Munoz FM: The impact of influenza in children. Semin Pediatr Infect Dis 2002;13:72-78.

54 Update: Outbreak of severe acute respiratory syndrome - worldwide, 2003. MMWR Morb Mortal Wkly Rep 2003;52:241-246, 248.

55 Rezza G, Nicoletti L, Angelini R, et al: Infection with chikungunya virus in Italy: an outbreak in a temperate region. Lancet 2007; 370:1840-1846.
Valles X, Sanchez F, Panella H, et al: Imported tuberculosis: an emerging disease in industrialised countries. Med Clin (Barc) 2002;118:376-378.

57 Outbreak of polio in adults - Namibia, 2006. MMWR Morb Mortal Wkly Rep 2006;55: 1198-1201.

58 Update: measles among children adopted from China. MMWR Morb Mortal Wkly Rep 2004;53:459.

59 Oxford JS, Sefton A, Jackson R, et al: World War I may have allowed the emergence of 'Spanish' influenza. Lancet Infect Dis 2002; 2:111-114.

60 Reed KD, Melski JW, Graham MB, et al: The detection of monkeypox in humans in the Western Hemisphere. N Engl J Med 2004; 350:342-350

61 McDonald LC, Killgore GE, Thompson A, et al: An epidemic, toxin gene-variant strain of Clostridium difficile. N Engl J Med 2005;353: 2433-2441.

62 Noblett SE, Welfare M, Seymour K: The role of surgery in Clostridium difficile colitis. BMJ 2009;338:b1563.

63 Currier JS, Havlir DV: Complications of HIV disease and antiretroviral therapy. Top HIV Med 2009;17:57-67.

64 Moylett EH, Shearer WT: HIV: clinical manifestations. J Allergy Clin Immunol 2002; 110:3-16.

65 Cooper CR Jr, McGinnis MR: Pathology of Penicillium marneffei. An emerging acquired immunodeficiency syndrome-related pathogen. Arch Pathol Lab Med 1997;121: 798-804.

66 Sallon S, Deckelbaum RJ, Schmid II, et al: Cryptosporidium, malnutrition, and chronic diarrhea in children. Am J Dis Child 1988; 142:312-315.

67 Goossens H, Ferech M, Vander SR, Elseviers $\mathrm{M}$ : Outpatient antibiotic use in Europe and association with resistance: a cross-national database study. Lancet 2005;365:579-587.

68 McCaig LF, Besser RE, Hughes JM: Antimicrobial drug prescription in ambulatory care settings, United States, 1992-2000. Emerg Infect Dis 2003;9:432-437.

69 Litzow JM, Gill CJ, Mantaring JB, et al: High frequency of multidrug-resistant Gram-negative rods in 2 neonatal intensive care units in the Philippines. Infect Control Hosp Epidemiol 2009;30:543-549.

70 Kassenborg HD, Smith KE, Vugia DJ, et al: Fluoroquinolone-resistant Campylobacter infections: eating poultry outside of the home and foreign travel are risk factors. Clin Infect Dis 2004;38(suppl 3):S279-S284.

71 Molbak K, Baggesen DL, Aarestrup FM, et al: An outbreak of multidrug-resistant, quinolone-resistant Salmonella enterica serotype typhimurium DT104. N Engl J Med 1999; 341:1420-1425

72 Hamer DH, Gill CJ: From the farm to the kitchen table: the negative impact of antimicrobial use in animals on humans. Nutr Rev 2002;60:261-264.
3 Fey PD, Safranek TJ, Rupp ME, et al: Ceftriaxone-resistant salmonella infection acquired by a child from cattle. N Engl J Med 2000;342:1242-1249.

74 Hennessy TW, Hedberg CW, Slutsker L, et al: A national outbreak of Salmonella enteritidis infections from ice cream. The Investigation Team. N Engl J Med 1996;334:1281-1286.

75 Thompson WW, Shay DK, Weintraub E, et al: Mortality associated with influenza and respiratory syncytial virus in the United States. JAMA 2003;289:179-186.

76 Glezen WP, Taber LH, Frank AL, et al: Influenza virus infections in infants. Pediatr Infect Dis J 1997;16:1065-1068.

77 Glezen WP, Couch RB: Interpandemic influenza in the Houston area, 1974-76. N Engl J Med 1978;298:587-592.

78 Hurwitz ES, Haber M, Chang A, et al: Studies of the 1996-1997 inactivated influenza vaccine among children attending day care: immunologic response, protection against infection, and clinical effectiveness. J Infect Dis 2000;182:1218-1221.

79 Neuzil KM, Zhu Y, Griffin MR, et al: Burden of interpandemic influenza in children younger than 5 years: a 25 -year prospective study. J Infect Dis 2002;185:147-152.

-80 Glezen WP, Decker M, Joseph SW, Mercready RG Jr: Acute respiratory disease associated with influenza epidemics in Houston, 1981-1983. J Infect Dis 1987;155:11191126.

81 Heikkinen T: Influenza in children. Acta Paediatr 2006;95:778-784.

-82 Munoz FM: Influenza virus infection in infancy and early childhood. Paediatr Respir Rev 2003;4:99-104.

83 O’Brien KL, Walters MI, Sellman J, et al: Severe pneumococcal pneumonia in previously healthy children: the role of preceding influenza infection. Clin Infect Dis 2000;30: 784-789.

84 Mullooly JP, Barker WH: Impact of type A influenza on children: a retrospective study. Am J Public Health 1982;72:1008-1016.

-85 Glezen WP: Modifying clinical practices to manage influenza in children effectively. Pediatr Infect Dis J 2008;27:738-743.

86 Taubenberger JK, Morens DM: The pathology of influenza virus infections. Annu Rev Pathol 2008;3:499-522.

87 Fauci AS: Emerging and re-emerging infectious diseases: influenza as a prototype of the host-pathogen balancing act. Cell 2006;124: 665-670.

88 Thompson WW, Shay DK, Weintraub E, et al: Mortality associated with influenza and respiratory syncytial virus in the United States. JAMA 2003;289:179-186.

89 Johnson NP, Mueller J: Updating the accounts: global mortality of the 1918-1920 'Spanish' influenza pandemic. Bull Hist Med 2002;76:105-115. 
-90 Fiore AE, Shay DK, Broder K, et al: Preven- 105 Morens DM, Taubenberger JK, Fauci AS: tion and control of influenza: recommendations of the Advisory Committee on Immunization Practices (ACIP), 2008. MMWR Recomm Rep 2008;57:1-60.

>1 Neuzil KM, Wright PF, Mitchel EF Jr, Griffin MR: The burden of influenza illness in children with asthma and other chronic medical conditions. J Pediatr 2000;137: 856-864.

$\checkmark 92$ Morens DM, Taubenberger JK, Fauci AS: The persistent legacy of the 1918 influenza virus. N Engl J Med 2009;361:225-229.

$\checkmark 93$ Rothberg MB, Haessler SD, Brown RB: Complications of viral influenza. Am J Med 2008;121:258-264.

94 Poehling KA, Edwards KM, Weinberg GA, et al: The underrecognized burden of influenza in young children. N Engl J Med 2006; 355:31-40.

-95 Heikkinen T, Silvennoinen H, Peltola V, et al: Burden of influenza in children in the community. J Infect Dis 2004;190:13691373.

$>96$ Neuzil KM, Mellen BG, Wright PF, et al: The effect of influenza on hospitalizations, outpatient visits, and courses of antibiotics in children. N Engl J Med 2000;342:225231.

-97 Ploin D, Gillet Y, Morfin F, et al: Influenza burden in febrile infants and young children in a pediatric emergency department. Pediatr Infect Dis J 2007;26:142-147.

-98 Coffin SE, Zaoutis TE, Rosenquist AB, et al: Incidence, complications, and risk factors for prolonged stay in children hospitalized with community-acquired influenza. Pediatrics 2007;119:740-748.

$\checkmark 99$ Chiu SS, Tse CY, Lau YL, Peiris M: Influenza A infection is an important cause of febrile seizures. Pediatrics 2001;108:E63.

100 Togashi T, Matsuzono Y, Narita M, Morishima T: Influenza-associated acute encephalopathy in Japanese children in 19942002. Virus Res 2004;103:75-78.

101 Newland JG, Laurich VM, Rosenquist AW, et al: Neurologic complications in children hospitalized with influenza: characteristics, incidence, and risk factors. J Pediatr 2007;150:306-310.

-102 Schrag SJ, Shay DK, Gershman K, et al: Multistate surveillance for laboratory-confirmed, influenza-associated hospitalizations in children: 2003-2004. Pediatr Infect Dis J 2006;25:395-400.

-103 Schwarzmann SW, Adler JL, Sullivan RJ Jr, Marine WM: Bacterial pneumonia during the Hong Kong influenza epidemic of 1968-1969. Arch Intern Med 1971;127: 1037-1041.

104 Hageman JC, Uyeki TM, Francis JS, et al: Severe community-acquired pneumonia due to Staphylococcus aureus, 2003-04 influenza season. Emerg Infect Dis 2006;12: 894-899. Predominant role of bacterial pneumonia as a cause of death in pandemic influenza: implications for pandemic influenza preparedness. J Infect Dis 2008;198:962-970.

06 Severe methicillin-resistant Staphylococcus aureus community-acquired pneumonia associated with influenza - Louisiana and Georgia, December 2006-January 2007. MMWR Morb Mortal Wkly Rep 2007;56: 325-329.

107 Finelli L, Fiore A, Dhara R, et al: Influenzaassociated pediatric mortality in the United States: increase of Staphylococcus aureus coinfection. Pediatrics 2008;122:805-811.

108 Morens DM, Folkers GK, Fauci AS: Emerging infections: a perpetual challenge. Lancet Infect Dis 2008;8:710-719.

109 Glezen WP, Greenberg SB, Atmar RL, et al: Impact of respiratory virus infections on persons with chronic underlying conditions. JAMA 2000;283:499-505.

110 Hartert TV, Neuzil KM, Shintani AK, et al: Maternal morbidity and perinatal outcomes among pregnant women with respiratory hospitalizations during influenza season. Am J Obstet Gynecol 2003;189:1705-1712.

111 Cox S, Posner SF, McPheeters M, et al: Hospitalizations with respiratory illness among pregnant women during influenza season. Obstet Gynecol 2006;107:1315-1322.

112 Neurologic complications associated with novel influenza $\mathrm{A}(\mathrm{H} 1 \mathrm{~N} 1)$ virus infection in children - Dallas, Texas, May 2009. MMWR Morb Mortal Wkly Rep 2009;58: 773-778.

113 Preliminary analysis of influenza $\mathrm{A}(\mathrm{H} 1 \mathrm{~N} 1) \mathrm{v}$ individual and aggregated case reports from EU and EFTA countries. Euro Surveill 2009;14:19238.

114 Smallman-Raynor M, Cliff AD: Avian influenza A (H5N1) age distribution in humans. Emerg Infect Dis 2007;13:510-512.

115 Izurieta HS, Thompson WW, Kramarz P, et al: Influenza and the rates of hospitalization for respiratory disease among infants and young children. N Engl J Med 2000; 342:232-239.

116 O’Brien MA, Uyeki TM, Shay DK, et al: Incidence of outpatient visits and hospitalizations related to influenza in infants and young children. Pediatrics 2004;113:585593.

117 Louie JK, Schechter R, Honarmand S, et al: Severe pediatric influenza in California, 2003-2005: implications for immunization recommendations. Pediatrics 2006; 117:e610-e618.

118 Glezen WP, Decker M, Perrotta DM: Survey of underlying conditions of persons hospitalized with acute respiratory disease during influenza epidemics in Houston, 1978-1981. Am Rev Respir Dis 1987;136: $550-555$.
119 Ploin D, Liberas S, Thouvenot D, et al: Influenza burden in children newborn to eleven months of age in a pediatric emergency department during the peak of an influenza epidemic. Pediatr Infect Dis J 2003; 22:S218-S222.

120 Simonsen L, Fukuda K, Schonberger LB, Cox NJ: The impact of influenza epidemics on hospitalizations. J Infect Dis 2000;181: 831-837.

121 Quach C, Piche-Walker L, Platt R, Moore D: Risk factors associated with severe influenza infections in childhood: implication for vaccine strategy. Pediatrics 2003; 112:e197-e201.

122 Bhat N, Wright JG, Broder KR, et al: Influenza-associated deaths among children in the United States, 2003-2004. N Engl J Med 2005;353:2559-2567.

123 American Academy of Pediatrics: Pandemic influenza: warning, children at-risk. Trust for America's Health, AAP, 2007.

124 Ghendon YZ, Kaira AN, Elshina GA: The effect of mass influenza immunization in children on the morbidity of the unvaccinated elderly. Epidemiol Infect 2006;134: 71-78.

125 Reichert TA, Sugaya N, Fedson DS, et al: The Japanese experience with vaccinating schoolchildren against influenza. N Engl J Med 2001;344:889-896

126 Monto AS, Davenport FM, Napier JA, Francis T Jr: Modification of an outbreak of influenza in Tecumseh, Michigan by vaccination of schoolchildren. J Infect Dis 1970; 122:16-25.

127 Glezen WP: Universal influenza vaccination and live attenuated influenza vaccination of children. Pediatr Infect Dis J 2008; 27:S104-S109.

128 Prevention and control of influenza: recommendations of the Advisory Committee on Immunization Practices (ACIP). MMWR Recomm Rep 1999;48:1-28.

129 Prevention of influenza: recommendations for influenza immunization of children, 2008-2009. Pediatrics 2008;122:1135-1141.

130 Mirza A, Subedar A, Fowler SL, et al: Influenza vaccine: awareness and barriers to immunization in families of children with chronic medical conditions other than asthma. South Med J 2008;101:1101-1105.

131 Taubenberger JK, Morens DM: Pandemic influenza - including a risk assessment of H5N1. Rev Sci Tech 2009;28:187-202.

132 Mermel LA: Swine-origin influenza virus in young age groups. Lancet 2009;373: 2108-2109.

133 Gregg MB, Hinman AR, Craven RB: The Russian flu. Its history and implications for this year's influenza season. JAMA 1978; 240:2260-2263.

134 Kilbourne ED: Influenza pandemics of the 20th century. Emerg Infect Dis 2006;12:914. 
135 Taubenberger JK, Morens DM: 1918 influenza: the mother of all pandemics. Emerg Infect Dis 2006;12:15-22.

-136 Smith GJ, Bahl J, Vijaykrishna D, et al: Dating the emergence of pandemic influenza viruses. Proc Natl Acad Sci USA 2009;106: 11709-11712.

137 Stadler K, Masignani V, Eickmann M, et al: SARS - beginning to understand a new virus. Nat Rev Microbiol 2003;1:209-218.

138 Finlay BB, See RH, Brunham RC: Rapid response research to emerging infectious diseases: lessons from SARS. Nat Rev Microbiol 2004;2:602-607.

139 Woods CR, Abramson JS: The next influenza pandemic: will we be ready to care for our children? J Pediatr 2005;147:147-155.

140 Breiman RF, Nasidi A, Katz MA, et al: Preparedness for highly pathogenic avian influenza pandemic in Africa. Emerg Infect Dis 2007;13:1453-1458.

141 Fauci AS: Pandemic influenza threat and preparedness. Emerg Infect Dis 2006;12: 73-77.

142 Morens DM, Taubenberger JK, Folkers GK, Fauci AS: An historical antecedent of modern guidelines for community pandemic influenza mitigation. Public Health Rep 2009; 124:22-25.

143 Nguyen-Van-Tam JS, Hampson AW: The epidemiology and clinical impact of pandemic influenza. Vaccine 2003;21:17621768.

144 Nicoll A: Children, avian influenza H5N1 and preparing for the next pandemic. Arch Dis Child 2008;93:433-438.

145 Oshitani H, Kamigaki T, Suzuki A: Major issues and challenges of influenza pandemic preparedness in developing countries. Emerg Infect Dis 2008;14:875-880.

146 Murray CJ, Lopez AD, Chin N, et al: Estimation of potential global pandemic influenza mortality on the basis of vital registry data from the 1918-20 pandemic: a quantitative analysis. Lancet 2006;368:22112218.

147 World Health Organization: Cumulative number of confirmed human cases of avian influenza A/(H5N1) reported to WHO. Geneva, WHO, 2009.

148 Epidemiology of WHO-confirmed human cases of avian influenza $\mathrm{A}(\mathrm{H} 5 \mathrm{~N} 1)$ infection. Wkly Epidemiol Rec 2006;81:249-257.
149 Uyeki TM: Global epidemiology of human infections with highly pathogenic avian influenza A (H5N1) viruses. Respirology 2008;13(suppl 1):S2-S9.

150 Sedyaningsih ER, Isfandari S, Setiawaty V, et al: Epidemiology of cases of H5N1 virus infection in Indonesia, July 2005-June 2006. J Infect Dis 2007;196:522-527.

151 Dawood FS, Jain S, Finelli L, Shaw MW, et al: Emergence of a novel swine-origin influenza A (H1N1) virus in humans. N Engl J Med 2009;360:2605-2615.

152 Update: novel influenza A (H1N1) virus infection - Mexico, March-May, 2009. MMWR Morb Mortal Wkly Rep 2009;58: 585-589.

153 Centers for Disease Control: CDC - Influenza (flu). Weekly report. Influenza Summary Update Week 29, 2008-2009.

154 Jamieson DJ, Honein MA, Rasmussen SA, et al: H1N1 2009 influenza virus infection during pregnancy in the USA. Lancet 2009; 374:451-458.

155 Chowell G, Bertozzi SM, Colchero MA, et al: Severe respiratory disease concurrent with the circulation of H1N1 influenza. N Engl J Med 2009;361:674-679.

156 Kawachi S, Luong ST, Shigematsu M, et al: Risk parameters of fulminant acute respiratory distress syndrome and avian influenza (H5N1) infection in Vietnamese children. J Infect Dis 2009;200:510-515.

157 World Health Organization: Avian influenza: assessing the pandemic threat. Geneva, WHO, 2005.

-158 Trifonov V, Khiabanian H, Rabadan R: Geographic dependence, surveillance, origins of the 2009 influenza A (H1N1) virus. N Engl J Med 2009;361:115-119.

159 Khan K, Arino J, Hu W, et al: Spread of a novel influenza A (H1N1) virus via global airline transportation. N Engl J Med 2009; 361:212-214.

160 World Health Organization. Influenza A(H1N1) - update 38. Geneva, WHO, 2009.

161 Swine-origin influenza A (H1N1) virus infections in a school - New York City, April 2009. MMWR Morb Mortal Wkly Rep 2009;58:470-472.

162 Human infection with new influenza A (H1N1) virus: clinical observations from a school-associated outbreak in Kobe, Japan, May 2009. Wkly Epidemiol Rec 2009;84: 269-271.

163 Smith A, Coles S, Johnson S, et al: An outbreak of influenza $\mathrm{A}(\mathrm{H} 1 \mathrm{~N} 1) \mathrm{v}$ in a boarding school in South East England, May-June 2009. Euro Surveill 2009;14:19263.
164 Sypsa V, Hatzakis A: School closure is currently the main strategy to mitigate influenza $\mathrm{A}(\mathrm{H} 1 \mathrm{~N} 1) \mathrm{v}$ : a modeling study. Euro Surveill 2009;14:19240.

165 World Health Organization: Pandemic influenza in pregnant women. WHO pandemic (H1N1) 2009 briefing note 5. Geneva, WHO, 2009.

166 Martinello RA: Preparing for avian influenza. Curr Opin Pediatr 2007;19:64-70.

167 Kitching A, Roche A, Balasegaram S, et al: Oseltamivir adherence and side effects among children in three London schools affected by influenza A(H1N1)v, May 2 . Euro Surveill 2009;14:19287.

168 Antiviral therapy and prophylaxis for influenza in children. Pediatrics 2007;119: 852-860.

169 Update: infections with a swine-origin influenza A (H1N1) virus - United States and other countries, April 28, 2009. MMWR Morb Mortal Wkly Rep 2009;58:431-433.

170 Principi N, Esposito S, Gasparini R, et al: Burden of influenza in healthy children and their households. Arch Dis Child 2004; 89:1002-1007.

171 Meissner HC: Influenza vaccines: a pediatric perspective. Curr Opin Pediatr 2007;19: 58-63.

172 Lin JC, Nichol KL: Excess mortality due to pneumonia or influenza during influenza seasons among persons with acquired immunodeficiency syndrome. Arch Intern Med 2001;161:441-446.

173 Madhi SA, Schoub B, Simmank K, et al: Increased burden of respiratory viral associated severe lower respiratory tract infections in children infected with human immunodeficiency virus type-1. J Pediatr 2000;137:78-84.

174 Madhi SA, Ramasamy N, Bessellar TG, et al: Lower respiratory tract infections associated with influenza $A$ and $B$ viruses in an area with a high prevalence of pediatric human immunodeficiency type 1 infection. Pediatr Infect Dis J 2002;21:291-297.

175 Migliori GB, Sotgiu G, Lange C, Macgregor-Skinner G: Defining priorities: swine-origin H1N1 and the MDR-TB epidemic. Lancet 2009;373:2108.

176 Muscat M, Hartvig Christiansen A, Bottiger BE, et al: A cluster of measles cases in Denmark following importation, January and February 2008. Euro Surveill 2008; 13(9):pii 8050. 